\title{
Abengalbón, O Mouro Amigo do Cid*
}

María de la Concepción Piñero Valverde**

RESUMO: O poema de Mio Cid apresenta um caso interessante de aliança e amizade pessoal entre diferentes grupos étnicos e religiosos, na Espanha medieval. Abengalbón, senhor mouro de molina, é visto pelo poeta não somente como amigo generoso do Cid, mas ainda como alguém que, graças à sua lealdade, deve ser lembrado com reverência, ao passo que alguns personagens cristãos são retratados como figuras mesquinhas e traiçoeiras. Também no Romancero e em outras obras da literatura espanhola medieval são apresentados casos de convivência amistosa entre cristãos e mouros.

$\mathrm{Na}$ Espanha medieval, a fronteira entre os terrritórios cristãos e mouros obrigou ambos os grupos a manterem relações constantes. Tais relações, ao contrário do que se poderia pensar à primeira vista, nem sempre foram de conflito. O autor do Poema de Mio Cid (PMC), o único grande exemplo de épica medieval espanhola, traz um supreendente exemplo de benevolência entre os grupos rivais. Isso se dá ao tratar da figura de Abengalbón, aliado e amigo fraterno do Cid.

O nome de Abengalbón aparece no segundo e no terceiro "cantar" do PMC, que o retratam como senhor de Molina, vila situada no

** Profal de literatura Espanhola da FFLCH da Universidade de São Paulo. 
caminho de Castela para Valença. Abengalbón é homem de paz e o próprio Cid logo reconhece essa grande qualidade de seu amigo:

\author{
"vayades a Molina que yaze mas adelant, \\ tienela Avengalvon -mio amigo es de paz-" (v. 1463-1464)
}

Abengalbón também proclama sua forte amizade pelo Cid:

"saliolos reçebir con grant gozo que faze:

¿Venides, los vassallos de mio amigo natural?" (v. 1477-1479)

A apresentação, no PMC, da figura de Abengalbón se faz no episódio em que o Cid, desterrado pelo rei de Castela, pede ao amigo mouro que proteja sua mulher, Ximena, e suas filhas, Elvira e Sol, e que as escolte até Valença. O mouro amigo não somente cumpre de bom grado o encargo, como leva a generosidade muito além da estrita obrigação. Ao descrever os encontros entre os emissários do Cid e o senhor de Molina, o PMC registra a saudação então habitualmente praticada pelos muçulmanos:

"Quando lego Avengalvon dont a ojo [1o] ha sonrrisando se de la boca hivalo abraçar, en el ombro lo saluda ca tal es su husaje." (v. 1517-1519)

O poeta alude, repetidamente, à lealdade de Abengalbón:

"Hy [a] Avengalvon amigol sodes sin falla! (v. 1528)

el moro Avengalvon bien los sirvie sin falla," (v. 1551)

Depois desse episódio, Abengalbón reaparece no PMC por ocasião do regresso a Castela dos infantes de Carrión, genros do Cid. Voltavam acompanhados de suas esposas e, ao passar pelas terras de Molina, valem-se da recomendação feita pelo sogro ao fiel amigo, a quem pedia que os acompanhasse até chegarem a Medina: 
"Por Molina iredes, i yazredes una noch, saludad a mio amigo el moro Avengalvon; reçiba a mios yernos commo el pudier mejor." (v. 2635-2637)

O senhor de Molina, por sua vez, alegra-se com a nova mensagem do Cid:

"El moro quando lo sopo plogol de coraçon, saliolos reçebir con grandes avorozes;

¡Dios, que bien los sirvio a todo so sabor!” (v. 2648-2650)

É durante a viagem de escolta com os infantes que Abengalbón descobre a traição que estes lhe preparam, para matá-lo. Um mouro ladino (isto é, versado na língua dos cristãos), escuta a conversa dos hóspedes e a conta a seu senhor, que abandona os traidores e os repreende severamente:

"Quando esta falssedad dizien los de Carrion

un moro latinado bien gelo entendio;

non tiene poridad, dixolo [a] Avengalvon:

'Acayaz, curiate destos, ca eres mio señor:

tu muert oi conssejar a los ifantes de Carrion.'

El moro Avengalvon mucho era buen barragan, con dozientos que tiene iva cavalgar.

Armas iva teniendo, paros ante los ifantes:

de lo que el moro dixo a los ifantes non plaze:" (v. 2666-2674)

A última vez que Abengalbón aparece no PMC é durante a passagem das filhas Cid por suas terras. Isto se dá quando são afrontadas e abandonadas por seus maridos (episódio chamado de "afrenta de Corpes"). O senhor de Molina acolhe as filhas do amigo sempre com a habitual generosidade: 
"e de Medina a Molina en otro dia van.

Al moro Avengalvon de coraçon le plaz,

saliolos a reçebir de buena voluntad;

por amor de mio Çid rica çena les da." (v. 2880-2883)

A sincera amizade entre Abengalbón e o Cid não exclui, por outro lado, a conveniência, para ambos, do acordo que os aproxima. O senhor mouro vê no guerreiro castelhano um poderoso aliado, cuja benevolência seria temerário desprezar. Neste sentido podem interpretar-se estes versos do PMC:

"ondrar vos hemos todos ca tal es la su auze,

mager que mal le queramos non gelo podremos $\mathrm{F}[\mathrm{a}] \mathrm{r} . "$

(v. 1523-1524)

Também o Cid tem em vista razões práticas em sua aliança com o mouro. Este, como senhor de Molina, defende posição estratégica entre as terras cristãs e a praça de Valença, conquistada pelo Cid, mas isolada de Castela, cuja fronteira então, como assinala o Poema, corria aproximadamente ao longo do alto Douro. Abengalbón é, as$\operatorname{sim}$, o elo indispensável que permite as comunicações entre Valença e o território castelhano. Nota-se, portanto, que é a partir de necessidades estratégicas que se estabelece inicialmente a relação entre o Cid e Abengalbón, relação que o conhecimento mútuo irá transformando em estima e em amizade pessoal.

Abengalbón é uma das figuras mais louvadas no PMC. A obra o descreve como realista (característica que o poeta considera grande virtude), magnânimo, valente, comedido e compassivo. Não é somente um aliado: suas relações com o Cid são genuinamente afetuosas e sua lealdade para com ele contrasta com a traição dos infantes cristãos. Como personagem do poema, representa a lembrança histórica de alguém com quem os ouvintes estavam familiarizados: o mouro nobre, amigo dos cristãos, com os quais vivia em paz e aliança. Ao apresentá-lo assim, o poeta não somente expressa o conceito de que 
entre os adversários havia pessoas dignas do maior respeito, mas ressalta a conveniência de buscar aliados entre os senhores da Espanha árabe, Al-Andalus, preferíveis, muitas vezes, a nobres cristãos de insegura lealdade, como os infantes de Carrión. Abengalbón, porém, não intervém com armas ao lado do Cid. É "amigo de paz", ou seja, tem com ele uma relação de mútua defesa, e não de vassalagem.

Muito se tem discutido quanto à existência e identidade histórica de Abengalbón. Menéndez Pidal pesquisou sua identidade, chegando à conclusão de que foi figura histórica, que viveu na região de Molina, possivelmente nos tempos do Cid. Nessa região há topônimos como Mingalbón e Torre de Mingalbón. Sancho Izquierdo diz que no século XI Molina tinha reis próprios, embora tributários do rei de Valença. Os três últimos reis de Molina, antes da conquista cristã, foram Hulacao, Abehomar e Abecanon o Abencanho. É possível que este último fosse o Abengalbón do Poema. Mas para o citado crítico é muito discutível que o rei de Molina, sendo tributário do de Valença, fosse amigo do Cid. Entre os que identificam a figura do mouro do Poema e o último rei de Molina está Huici Miranda. Para este crítico, seu verdadeiro nome seria Azzun, embora o conhecessem melhor pelo nome de seu pai, Ibn Galbun. A este rei se faz referência na crônica árabe de al-Bayan al-Mugrib, onde se nota que ele e sua família, mesmo depois da conquista cristã de Molina, continuaram a viver na região. Embora aceite a historicidade do $\mathrm{PMC}$, Huici não acredita na veracidade dos elogios que nele se fazem ao mouro amigo, nem em sua fidelidade ao Cid.

Mas a historicidade de Abengalbón, como último senhor de Molina, levanta alguns problemas, quase todos tratados por María Eugenia Lacarra. Uma dessas questões é a de saber se poderia ter sido de Molina, como indica o PMC; outra, a de saber se é histórica sua relação com o Cid. Negando historicidade a toda a relação entre o Cid e os infantes de Carrión, Lacarra também a nega à relação entre os infantes e Abengalbón e opina que o autor do PMC se esforçou por acomodar ao tempo da poesia fatos históricos posteriores. Seu 
objetivo teria sido aludir ao senhorio de Molina que, depois da conquista cristã, coube, em 1173, a Pedro Manrique de Lara, casado com a infanta Sancha, bisneta do Cid. Considerando-se que a maior parte das menções a Abengalbón se relacionam com a "afrenta de Corpes", pensa a historiadora que o mouro amigo poderia ser figura oposta aos infantes de Carrión, embora construída sobre a lembrança do último rei mouro de Molina.

Quanto às crônicas medievais, cristãs e árabes, ainda que não façam referência concreta à amizade entre o Cỉ e Abengalbón, é certo que registram numerosos casos de convivência benévola entre cristãos e mouros. A Historia Roderici, por exemplo, trata extensamente da boa relação de Rodrigo (o futuro Cid) com o soberanò mouro de Saragoça. Basta citar alguns trechos: "Mu'tamin apreciaba mucho a Rodrigo, y le puso en lugar destacado colocándole al frente de su reino y de todo su territorio, y tomándole en todo de consejero". E mais adiante: "Con Mu'tamin estaba Rodrigo Díaz, que le servía fielmente, y cuidaba y protegía su reino y su tierra". Após a morte de Mu'tamin, o governo passou a seu filho e sucessor Musta'in, "con el que vivió Rodrigo con máximo honor y veneración en Zaragoza nueve meses". Essa mesma crônica cristã, que qualifica de generoso e de amigos esses muçulmanos, refere-se ao conde de Barcelona como arrogante e orgulhoso - e assim é lembrando o conde também no PMC (cf. FALQUÉ). Note-se também que o cronista cristão jamais formula a menor reprovação ao Cid pela amizade e pelo auxílio que prestava ao senhor mouro de Saragoça, em luta contra senhores cristãos. Para o cronista, sendo territórios fronteiriços, os reinos cristãos e mouros permitiam manter relações e até prestar serviço a alguém, qualquer que fosse sua crença religiosa.

A obra literária, em nosso caso o PMC, revela-se, pois, interpréte intuitivamente fiel de experiências então vividas. Abengalbón, mouro amigo, seria indício de uma convivência peninsular que o poeta ardorosamente exalta. Ao contrário da Chanson de Roland, onde não há exemplo de mouros apresentados de forma favorável, no PMC o 
mouro não só pode ser amigo e aliado, mas chega a proteger alguns cristãos da traição de outros.

Não faltam na literatura espanhola outras amostras de benevo1ência "de fronteira" entre cristãos e mouros. Sem falar no Abencerraje, que narra o nascimento da amizade entre Abindarráez e Rodrigo, basta pensar em algumas páginas do Romancero. Tomemos, para citar um caso, os lindos versos do Romance de Fajardo, onde o jogo de xadrez, empregado como fonte de solução de controvérsias territoriais, acaba por manifestar a profunda afeição de um rei mouro por aquele que poderia ser seu adversário:

"Jugando estaba el rey moro,

y aun al ajedrez un día,

con aquese buen Fajardo

con amor que le tenía.

Fajardo jugaba a Lorca,

y el rey moro a Almería;

jaque le dio con el roque,

el alférez le prendía.

A grandes voces dice el moro:

- La villa de Lorca es mía -.

Allí hablara Fajardo,

bien oiréis lo que decía:

- Calles, calles, señor rey,

no tomes la tal porfia,

que aunque me la ganases,

ella no se te daría;

caballeros tengo dentro

que te la defenderían-.

Alli hablara el rey moro,

bien oiréis lo que decia:

- No juguemos más, Fajardo 
ni tengamos más porfía, que sois tan buen caballero, que todo el mundo os temía". (cf. Santullano)

Esses testemunhos da literatura medieval permitem concluir que, se as relações entre cristãos e mouros, na Espanha, foram marcadas por episódios de conflito, tais episódios não geraram, necessariamente, desprezo recíproco ou ódio pessoal (cf. PIÑERO VALVERDE). Pelo contrário, a poesia e a história conservam a lembrança do mútuo desejo de encontrar espaços de convivência, onde pudessem florescer o respeito, o apreço e mesmo a fraterna amizade.

\begin{abstract}
RESUMEN: El Poema de Mio Cid presenta un caso interesante de alianza y amistad personal entre distintos grupos étnicos y religiosos en la España medieval. El poeta ve a Abengalbón, señor moro de Molina, no sólo como un amigo generoso de El Cid, sino como alguien que, gracias a su lealtad, debe ser recordado con reverencia, mientras que muestra a algunos personajes cristianos como figuras mezquinas y traicioneras. Otros casos de convivencia armoniosa entre cristianos y moros se presentan en el Romancero y otras obras de la literatura española medieval.
\end{abstract}

\title{
REFERÊNCIAS BIBLIOGRÁFICAS
}

FALQUÉ, Emma. Historia Roderici. Boletín de la Institución Fernán González, Consejo Superior de Investigaciones Científicas, $n$. 201, p. 339-375, 1983.

HUICI MIRANDA, Ambrosio. Un nuevo manuscrito de "al-Bayan al-Mugrib". Al-Andalus, n. 24, p. 81-84, 1959.

LACARRA, María Eugenia , El "PMC": Realidad histórica e ideología. Madrid: José Porrúa Turanzas Ed., 1980, p. 195-201.

MENÉNDEZ PIDAL, Ramón. Cantar de Mio Cid, III, $3^{\text {a }}$. ed. Madrid: Espasa-Calpe, 1956, p. 1212-1213. 
PIÑERO VALVERDE, María de la Concepción. "Nuevas de alent partes del mar": Aspecto de la convivencia entre cristianos y moros en el Poema de mio Cid. Romanische Forschungen, n. 101 (1), p. 1-13, 1989.

- Mudanças e rumos: o Ocidente medieval (séculos XIXIII) (em colaboração). Terra de fronteiras: a Espanha do século XI ao século XIII. Cotia: Íbis, 1997, p. 149-184.

SANCHO IZQUIERDO, Miguel. El Fuero de Molina de Aragón. Madrid: Lib. General de Victoriano Suárez, 1916, p. 14,16.

SANTULLANO, Luis (Ed.) Romancero Español. 6a. ed. Madrid: Aguilar, 1968, p. 626.

SMITH, Colin. Poema de Mio Cid. 9a. ed. Madrid: Cátedra, 1982. Todas as citações do PMC neste trabalho são feitas segundo esta edição. 